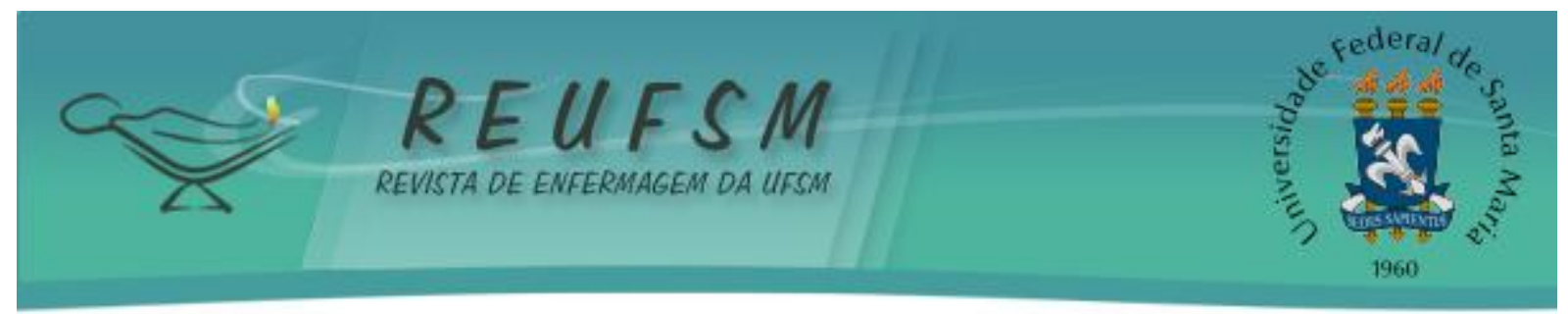

ARTIGO ORIGINAL

\title{
O CUIDAR DO IDOSO COM ALZHEIMER: SENTIMENTOS E EXPERIÊNCIAS VIVENCIADOS POR SEUS CUIDADORES*
}

\section{TAKING CARE OF THE ELDERLY WITH ALZHEIMER'S: FEELINGS AND EXPERIENCE REVEALED BY THEIR CAREGIVERS CUIDADO DEL ANCIANO ENFERMO DE ALZHEIMER: SENTIMIENTOS Y EXPERIENCIAS
VIVIDAS POR SUS CUIDADORES}

\author{
Lídia Gonçalves Rabelo de Souza Almeida ${ }^{1}$ \\ Mônica Gomes Jardim² \\ Elaine Cristina Dias Franco ${ }^{3}$
}

\section{Doi: $10.5902 / 2179769210023$}

RESUMO: Objetivo: apreender a percepção do cuidador em relação à experiência de cuidar do idoso com demência do tipo Alzheimer. Método: pesquisa qualitativa que teve como amostra oito cuidadores de pacientes com doença de Alzheimer de um município de Minas Gerais. Foram realizadas entrevistas a partir de um roteiro semiestruturado, no período de dezembro de 2012 a fevereiro de 2013. O material foi analisado por meio de técnica de Análise de Conteúdo. Resultados: foram evidenciadas as seguintes categorias: a doença no olhar do cuidador e a convivência com as limitações do paciente e do cuidador. Considerações finais: a necessidade de cuidados contínuos torna indispensável a presença de um cuidador que, com a progressão da doença, assumirá as tarefas de vida diária do paciente, necessitando de apoio assim como de esclarecimentos e informações referentes à doença.

Descritores: Cuidadores; Doença de alzheimer; Idoso.

ABSTRACT: Aim: to learn the perception of the caregiver in relation to the experience of taking care of the elderly with dementia of the Alzheimer type. Methods: qualitative study, with a sample of eight caregivers of patients with Alzheimer's disease in a city of Minas Gerais. Interviews were conducted with a semistructured script, from December 2012 to February 2013. The material was analyzed using the content analysis technique. Results: the following categories were identified: the disease in the caregiver's perspective, and living with the limitations of both patient and caregiver. Conclusions: the need for continuous care makes caregiver assistance indispensable and, as the disease progresses, the caregiver assumes the patient's activities of daily living. Therefore, support as well as education and information about the disease are needed.

Descriptors: Caregivers; Alzheimer disease; Aged.

RESUMEN: Objetivo: conocer la percepción del cuidador en relación a la experiencia de cuidado de ancianos con demencia de tipo Alzheimer. Metodología: estudio cualitativo con muestra de ocho cuidadores de pacientes con enfermedad de Alzheimer en un municipio de

\footnotetext{
* Artigo produzido a partir de pesquisa realizada como Trabalho de Conclusão de Curso de Graduação em Enfermagem da Universidade Federal de São João Del Rei (UFSJ). 1 Graduanda em Enfermagem. Universidade Federal de São João Del Rei (UFSJ). Divinópolis (MG), Brasil. Email: lidiagrsalmeida@hotmail.com

2 Enfermeira graduada na Universidade Federal de São João Del Rei (UFSJ). Divinópolis (MG), Brasil. E-mail: monica-jardim@hotmail.com

3 Enfermeira. Mestre em Promoção da saúde. Doutoranda em Enfermagem pela Universidade Federal de Minas Gerais (UFMG). Docente Assistente II do curso de Enfermagem da Universidade Federal de São João Del Rei (UFSJ). Orientadora da pesquisa. E-mail: elainefranco1@yahoo.com.br
} 


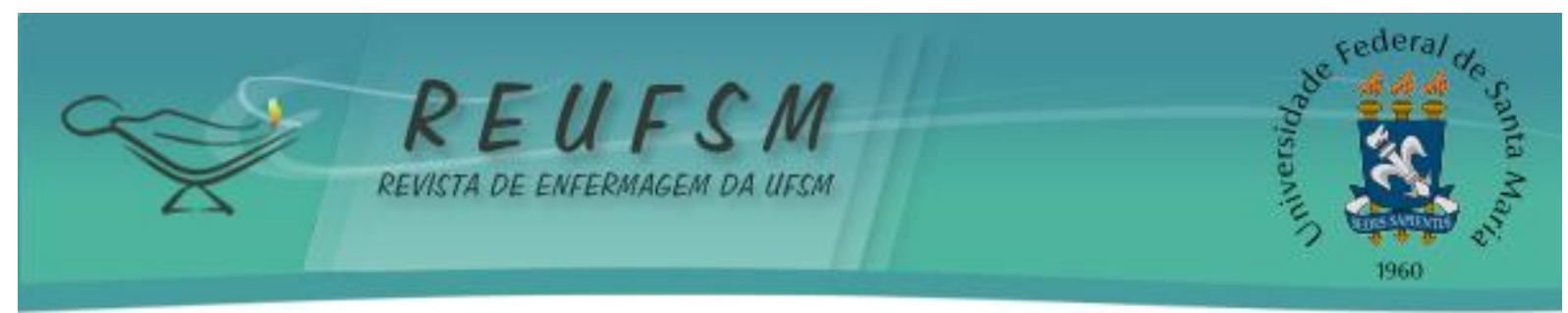

Minas Gerais (Brasil). Fueron realizadas entrevistas con guión semiestructurado entre diciembre de 2012 y febrero 2013. El material se analizó usando la técnica del Análisis de Contenido. Resultados: fueron identificadas las siguientes categorias: la enfermedad desde el punto de vista del cuidador y la convivencia con las limitaciones del paciente y del cuidador. Consideraciones finales: la necesidad de cuidados continuos hace indispensable la presencia de un cuidador que, con la evolución de la enfermedad, asumirá las tareas cotidianas del paciente, necesitando apoyo así como aclaraciones $e$ informaciones sobre la enfermedad. Descriptores: Cuidadores; Enfermedad de alzheimer; Anciano.

\section{INTRODUÇÃO}

Estratégias para envelhecer de forma saudável, direitos do cidadão idoso, doenças comuns na velhice e serviços de saúde para idosos são temas que se tornaram comuns nos estudos científicos e na mídia nos últimos anos, o que pode ser justificado pela transição epidemiológica e demográfica pela qual o Brasil e o mundo têm passado nas últimas décadas.

No Brasil e no mundo, a população, de forma geral, está ficando mais velha. Esse fato pode ser explicado, levando-se em consideração a redução das taxas de mortalidade e de fecundidade, o aumento da expectativa de vida e a melhoria das condições de saúde da população.

Associado ao processo de envelhecimento vivenciado pela população, observa-se um aumento do número de casos de demências, as quais normalmente são resultantes de uma série de estressores genéticos e ambientais, que variam com o tempo, idade e de indivíduo para indivíduo. ${ }^{2}$

Nesse ínterim, a doença de Alzheimer (DA) aparece como uma doença crônicodegenerativa com prevalência significativa na sociedade. Diante disso, projeções indicam que até o ano de 2025 vão existir cerca de 34 milhões de portadores de DA no mundo. ${ }^{3}$

No Brasil, apesar das estatísticas não serem precisas, estima-se que cerca de quinhentas mil pessoas sejam acometidas por essa patologia, o que causa impacto social, em decorrência dos custos diretos envolvidos no cuidado com os portadores. ${ }^{4}$

A DA foi descrita, pela primeira vez, em 1906 pelo neuropatologista alemão Alois Alzheimer e, em 1910, recebeu essa denominação por Kraepelin. ${ }^{5}$

A DA é uma doença neurodegenerativa caracterizada pela perda de memória que pode estar associada com afasia, apraxia e agnosia e somando-se a estas questões, tem-se a imprecisão das causas da DA e a ausência de cura. ${ }^{1}$

Composta de diversas manifestações clínicas e complicações, a doença de Alzheimer causa impacto tanto na vida do idoso portador quanto na do cuidador, além de repercussões no âmbito familiar e social. ${ }^{1,6}$ Quando a família não se organiza para atender a demanda de cuidados deste idosos, na maioria das vezes, outras instituições tem desempenhado esse papel.

Neste contexto, a família tem um papel essencial no processo de cuidar do seu idoso portador de Alzheimer, que se torna inteiramente dependente do cuidado de terceiros. 0 que se observa é que algumas famílias possuem condições de contratar uma pessoa para executar este papel de cuidador; muito embora, famílias com menor poder aquisitivo, em geral, destacam um de seus membros para essa atividade. ${ }^{7}$

Estudos recentes têm sinalizado que, normalmente, o cuidador familiar é carente de informações e de preparo para exercer o seu novo papel, necessitando, portanto, que os profissionais de saúde, entre eles, a equipe de enfermagem, o amparem nesse processo, para que se sintam seguros e confiantes. ${ }^{1,8}$

Assim como os portadores da DA, seus cuidadores também necessitam ter uma boa qualidade de vida para que possam continuar exercendo essa função no cuidado do doente 


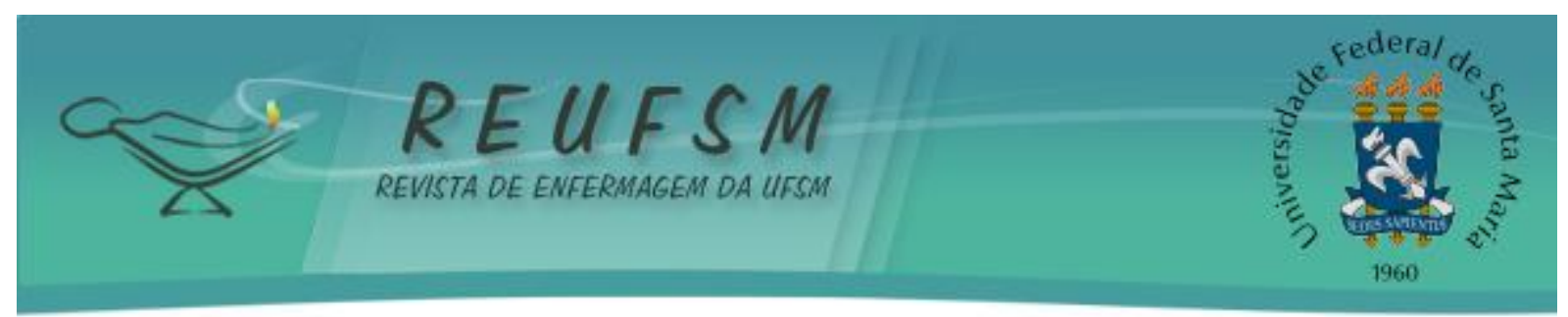

de maneira adequada, visto que estes também possuem as suas limitações e necessidades e o fato de assumir esse cuidado contínuo do doente pode repercutir no seu próprio adoecimento.

Nesse cenário, os profissionais de enfermagem devem estar atentos e intervir, quando necessário, tentando sensibilizar demais familiares para o cuidado do doente, ajudando-os a encontrarem formas de enfrentamento para as diversas situações consequentes da progressão da DA, evitando, assim, a sobrecarga de trabalho em apenas um cuidador. ${ }^{9}$ Assim, ao indicar o rumo dos cuidados para o cuidador familiar, o enfermeiro deve conhecer o que esse familiar sabe a respeito da doença de Alzheimer e seus cuidados específicos. ${ }^{8}$

Levando em consideração a relevância do tema e o aumento da expectativa de vida que permite ao idoso vivenciar processos de adoecimentos particulares a essa faixa etária, surgiu a inquietação de como o cuidador vivencia a doença de Alzheimer de seu familiar. Esse questionamento emerge da necessidade de cuidadores e dar voz a essas figuras para que elas possam retratar suas angústias, dificuldades, facilidades e possibilidades como cuidadores de idosos com Alzheimer.

Por meio dos enfoques citados anteriormente, objetivou-se com o estudo apreender a percepção do cuidador em relação à experiência de cuidar do idoso com demência do tipo Alzheimer.

\section{MÉTODO}

Trata-se de um estudo do tipo qualitativo, pelo fato de ele ser capaz de interpretar aspectos complexos do cotidiano de cuidadores de portadores da doença de Alzheimer. ${ }^{10}$ A coerência entre o objeto de estudo e o caminho metodológico foi determinante para a definição do tipo de estudo e instrumentos para a coleta de dados, sendo então utilizada a técnica de entrevista com roteiro semiestruturado.

Para a escolha dos participantes da pesquisa, foi solicitado junto à Secretaria Municipal de Saúde o número de idosos atendidos em todas as unidades de Atenção Primária do município. Foram selecionados as que apresentavam maior número de idosos em sua área de abrangência, sendo então escolhidas três unidades de Atenção Primária à Saúde, subdivididas em duas Estratégias de Saúde da Família (ESF) e uma equipe do Programa de Agentes Comunitários de Saúde (PACS).

Posteriormente à definição das unidades de saúde que fariam parte do cenário de estudo, foi estabelecido contato com as enfermeiras responsáveis pelas mesmas para que estas informassem o número de idosos com diagnóstico de DA acompanhados pela equipe, bem como o endereço e/ou número de telefone de cada indivíduo. Os dados foram repassados pelos agentes comunitários de saúde de cada microárea, pois não existe um registro individual e específico para os portadores da doença de Alzheimer; esse dado é registrado na Ficha de Cadastro Familiar. Por meio destas informações de idosos, foi efetuado contato com os cuidadores de portadores de DA, perfazendo inicialmente um total de treze possíveis sujeitos.

Foram utilizados como critérios para inclusão no estudo: ter maioridade; não apresentar deficiências físicas e cognitivas que pudessem impedir o entendimento e participação na presente pesquisa; apresentar características de cuidador familiar/principal, sendo este aquele que tem responsabilidades permanentes (total ou a maior parte) pelos cuidados do idoso dependente no domicílio. ${ }^{7}$

Para realizar as entrevistas foram estabelecidos contatos telefônicos com os possíveis participantes para agendamento da visita domiciliar, na qual foi apresentado o Termo de Consentimento Livre e Esclarecido, que, após sua leitura e concordância, foi 


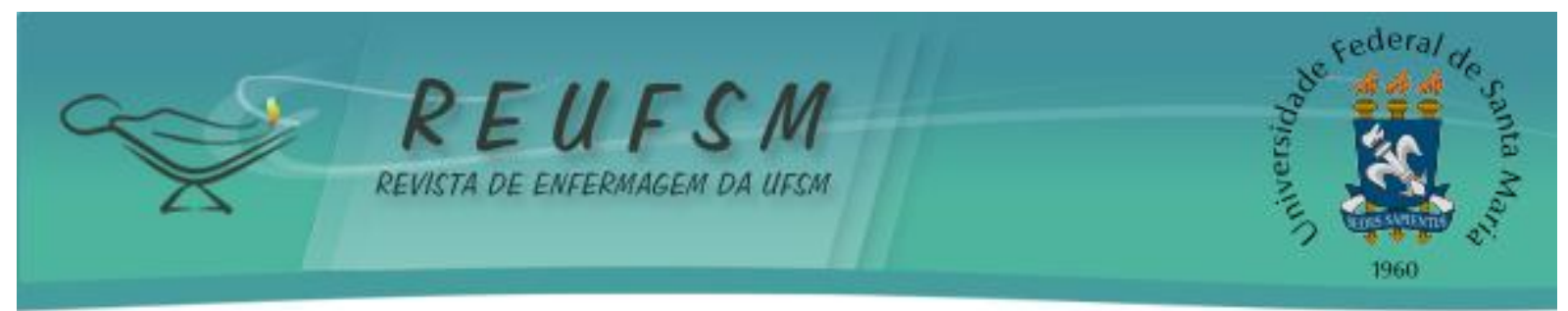

assinado pelos sujeitos da pesquisa. As entrevistas tiveram duração média de trinta minutos, foram gravadas mediante autorização prévia dos informantes e ocorreram no período de 27 de dezembro de 2012 a 16 de fevereiro de 2013.

A amostra final do estudo foi determinada a partir do critério de saturação, ou seja, no momento em que os relatos se tornaram semelhantes, foi finalizada a fase de coleta, o que permitiu a realização de oito entrevistas. ${ }^{11}$ Para a apresentação dos resultados e garantia do anonimato dos sujeitos, cada cuidador foi codificado com a letra $E$, seguida do número de sequência das entrevistas.

0 roteiro utilizado na coleta de dados foi composto de duas partes, sendo a primeira com questões referentes ao perfil do cuidador: idade, sexo, escolaridade, estado civil, tempo que exerce o papel de cuidador, remuneração e jornada de trabalho. A segunda parte foi composta por perguntas norteadoras que abordaram a percepção do cuidador em relação à doença de Alzheimer, a evolução da doença em seu cliente, finalizando com o questionamento sobre a experiência de cuidar do portador da DA.

Para a análise das informações que emergiram nas entrevistas foi utilizada a técnica de Análise de Conteúdo partindo de uma pré-análise a fim de organizar o material coletado, seguida de leituras flutuantes das respostas obtidas nas entrevistas, para posterior categorização das unidades de registro a qual resultou em duas categorias. ${ }^{12}$

Em atenção à Portaria 196/96 do Conselho Nacional de Saúde do Ministério da Saúde, que normatiza a pesquisa que envolve seres humanos, o estudo foi aprovado em 28 de setembro de 2012, pelo Comitê de Ética em Pesquisa da Universidade Federal de São João del-Rei, sob o registro $\mathrm{n}^{0}{ }^{1} 110.486 .{ }^{13}$

\section{RESULTADOS E DISCUSSÃO}

\section{Caracterização dos cuidadores e suas atividades}

A progressão da doença de Alzheimer faz com que os portadores se tornem dependentes de um cuidador que poderá ser formal ou informal. Os cuidadores formais são aqueles que possuem uma formação específica para o cuidado, enquanto que os informais são, na maioria das vezes, familiares, amigos, vizinhos e voluntários de grupos religiosos. ${ }^{5}$

Ao analisar as informações iniciais das entrevistas, constatou-se que os participantes possuiam idade entre 26 e 77 anos, sendo seis mulheres e dois homens, reafirmando a tendência de que o cuidado ao doente familiar é atribuição feminina. ${ }^{8}$ Quanto à escolaridade dos cuidadores, verificou-se que a maioria possui ensino fundamental incompleto, tendo um cuidador concluído o ensino superior. Dos oito cuidadores entrevistados, um não reside com o idoso portador da doença de Alzheimer.

Em relação ao tempo de cuidado e horas semanais dedicadas ao cuidado, verificou-se que nenhum dos entrevistados havia trabalhado como cuidador anteriormente e o tempo que exercia essa função variou de seis meses a dez anos. Cinco cuidadores, referiram dedicar integralmente o período diurno e noturno para as tarefas de cuidador(a); três dos entrevistados relataram não possuir folgas semanais e cinco não possuíam período de férias. Todos os cuidadores são familiares, mas apenas uma cuidadora recebia remuneração para exercer o trabalho, no valor de trezentos reais mensais. Em relação a posição familiar ocupada pelos cuidadores, sete eram filhos e um era cônjuge.

A partir das informações levantadas nas entrevistas constatou-se a proximidade dos resultados encontrados com dados que revelam que, no geral, os cuidadores são, em sua maioria, mulheres que ocupam a posição de esposas ou filhas casadas e que residem com o idoso doente. ${ }^{14}$ 


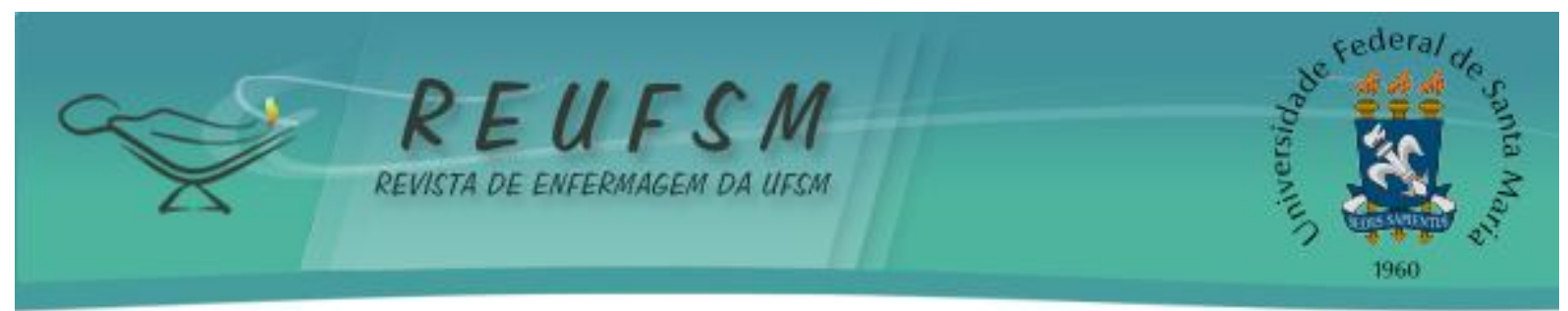

Esses cuidadores, como visto, sendo em sua maioria informais, muitas vezes carecem de um preparo adequado para estimular os exercícios indicados e os cuidados específicos de que esses idosos necessitam, acarretando, consequente déficit de conhecimento associados a doença, eventos de descompensação, que acometem os idosos com DA. ${ }^{8}$

A partir dos depoimentos dos informantes e da exploração do material emergiram duas categorias, a saber: a doença no olhar do cuidador e; a convivência com as limitações do paciente e do cuidador.

\section{A doença no olhar do cuidador}

Quando se trata de idoso com DA, em geral, o cuidado é exercido por um familiar. ${ }^{5,7} A$ escolha do cuidador encontra-se fundamentada no atendimento às necessidades advindas do processo de envelhecer somadas àquelas ocasionadas pela doença. $^{5}$

A responsabilidade desses familiares, que na maioria das vezes assumem o papel de cuidador, aumenta concomitantemente à progressão da doença, que exige uma supervisão e cuidados constantes ${ }^{6}$ que se tornam cada vez mais complexos, ocasionando um aumento da preocupação dos cuidadores com o doente. ${ }^{8}$

O Alzheimer evolui com o passar do tempo, o que lhe confere diferentes estágios de desenvolvimento com sinais e sintomas que perpassam a fase leve, moderada e severa da doença. No estágio leve, observam-se confusões e perda da memória, desorientação espacial, dificuldade progressiva no cotidiano diário, mudanças na personalidade e na capacidade de julgamento; no moderado percebem-se dificuldades nos atos de vida diária (banhar-se, vestir-se, alimentar-se), ansiedade, delírios e alucinações, agitação noturna, alteração do sono, dificuldade para reconhecer amigos e familiares; e, por fim, no estágio severo nota-se a diminuição acentuada do vocabulário, diminuição do apetite e do peso, descontrole urinário e fecal. ${ }^{7}$

Ressalte-se ainda que, em cada uma das etapas citadas acima há perda gradativa da autonomia para realização de atividades básicas da vida diária com consequente aumento das necessidades de se terem cuidadores para os portadores da doença de Alzheimer. ${ }^{15}$

O conhecimento sobre a DA para os cuidadores, muitas vezes, não está claro e aparece de forma confusa. De maneira geral, os cuidadores deste estudo mostram ter alguma informação sobre a doença, que adquiriram por meio da televisão, orientações médicas e pesquisas na internet, como observado no relato abaixo.

Eu estou pesquisando ainda. Já fui muito em assembleia, já fiz curso de cuidador, vejo entrevista na televisão. (E5)

A partir dos relatos dos entrevistados percebeu-se que eles compreendem e são capazes de identificar alguns sinais e sintomas da doença no cotidiano do idoso.

Os neurônios vão morrendo e a pessoa vai perdendo a coordenação [...]. (E2)

[...] um dia está bem, outro dia está mais triste, outro dia está agitado. (E4)

[...] é como se o cérebro estivesse diminuindo [...]. (E6) 


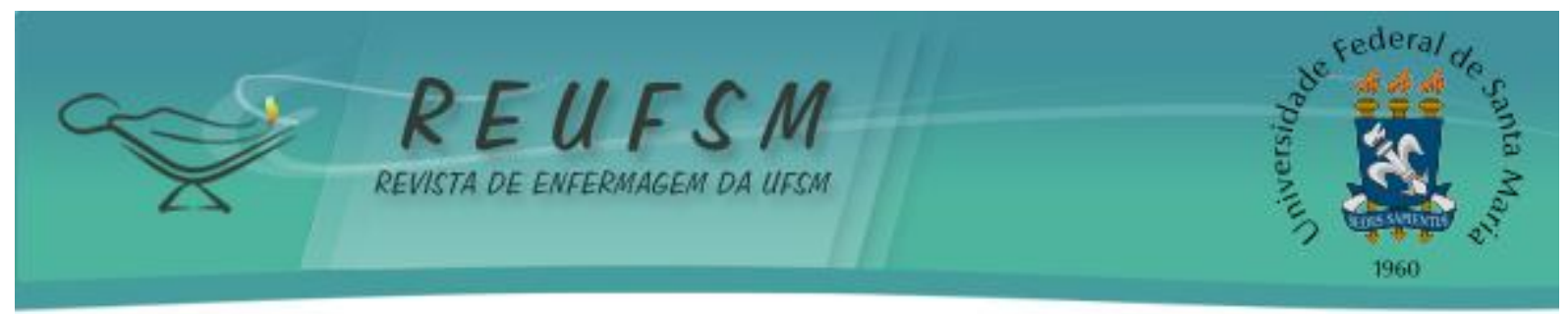

[...] a doença de Alzheimer é uma doença muito lenta [...] ela é evolutiva, evolui muito, mas, lentamente. (E7)

Além dos sinais e sintomas relatados pelos pacientes, foi possível identificar que eles associam, mesmo que equivocadamente, a depressão com o aparecimento da DA.

A doença de Alzheimer já vem com a depressão [...] a primeira vez que tem depressão, se tomar remédio, ela cura, mas, se tiver outra vez, então não tem jeito, ela vira Alzheimer, mesmo. (E1)

Ele tem o Alzheimer e com ele a depressão, aí ele melhorou, a depressão dele melhorou. (E3)

Aliada à progressão da doença, o idoso começa a perder a sua identidade, por passar a necessitar de cuidados para realização de atividades básicas de vida, assim como para tomada de decisão, principalmente quando já se encontra em estágios mais avançados. ${ }^{15}$ Nos relatos dos cuidadores percebeu-se referência à perda de memória e dificuldade progressiva nas atividades diárias dos pacientes portadores de DA.

[...] ela perdeu a capacidade de saber quem que é a pessoa, de escrever, de chamar, de fazer as necessidades que antes ela dava conta [...]. (E2)

Cada vez mais dependente. Assim, ela mudou muito, porque hoje ela não anda mais, às vezes não conhece a gente. Cada vez mais ela está mais esquecida. (E4)

Eu tenho percebido que ela não conhece ninguém, mesmo, nem a gente que está dia a dia ela não lembra da gente [...] ela não me conhece, ela num sabe quem que eu sou [...] a pessoa num lembra de nada. (E8)

Ressalta-se, então, que os cuidadores precisam apreender e compreender os aspectos relacionados à progressão da DA, visto que o conhecimento sobre a doença é primordial para a vida do doente e do cuidador para que se possa agir corretamente e realizar todas as atividades com segurança, sabedoria e paciência. ${ }^{1,16}$ Sendo assim, um cuidador que busca manter-se informado sobre as novidades e possíveis descobertas que a ciência possa trazer sobre a doença de Alzheimer torna-se uma pessoa ideal e capacitada para assistir diariamente esse idoso. ${ }^{1}$

\section{A convivência com as limitações do paciente e do cuidador}

A sobrecarga de trabalho que os cuidadores de doentes de Alzheimer enfrentam faz com que o cuidado seja consecutivo e rotineiro, exigindo além da habilidade, dedicação, compreensão e principalmente o exercício da paciência por parte desses indivíduos. ${ }^{17-18}$ É notório que o cuidado para com o doente de Alzheimer está relacionado ao exercício do amor e paciência. ${ }^{19}$

Ao serem questionados sobre como é cuidar de alguém que é portador da doença de Alzheimer, os cuidadores fizeram inferências sobre atitudes que refletiam dedicação, paciência, atenção, entre outras. 


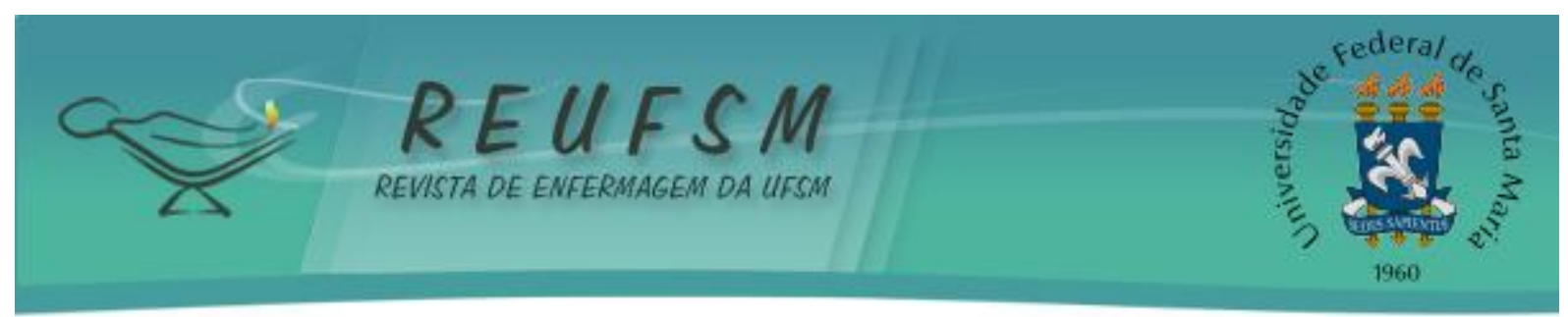

Você tem que ter paciência. Eu acho que a pessoa tem que ter paciência e tem que ter muito cuidado. (E1)

[...] às vezes, a gente perde um pouco a paciência, porque a gente tem que ter um monte de paciência, muita paciência [...] você tem que ter muita paciência mesmo, senão você não consegue não [...] quem não tiver paciência não consegue cuidar não, exige muito mesmo da gente. Mas, como diz é bom, não é ruim não. (E3)

Tem que ter muita paciência. (E6)

Está sendo uma experiência muito boa pra mim, porque testa a minha paciência. (E7)

De acordo com as entrevistas, evidenciou-se que o cuidar de uma pessoa com diagnóstico de DA exige atenção, solidariedade, paciência e dedicação. A assistência ao idoso merece a divisão de tarefas entre os familiares, já que os cuidados exigem atenção, causando grande desgaste físico e emocional para os cuidadores que lidam diretamente com o portador. ${ }^{20}$

É fato que, à medida que a doença progride, o cuidador passa a desenvolver tarefas que até então eram desempenhadas pelo idoso, aumentando sua responsabilidade em tarefas como higienização, banho e alimentação do portador. ${ }^{15}$

Ressalta-se também, a partir dos relatos dos cuidadores, que exercer essa tarefa do cuidado, com o passar do tempo, torna-se cansativo e desgastante, até porque na maioria dos casos esse cuidador não recebe ajuda de uma outra pessoa, não há divisão de tarefas e o cuidado precisa ser contínuo.

Tem que ter muita paciência. Muito complicado [...] porque você faz uma coisa e na mesma hora que você faz aquela certa coisa para pessoa ela já não lembra mais e refaz a mesma coisa várias vezes que é errada e aí você tem que interagir ou esperar um tempo, sair, esperar uns 10 minutos e voltar, porque senão você fica louco. (E2)

Quem não tiver paciência não consegue cuidar não, exige muito mesmo da gente. (E3)

Não é fácil não e para mim que tem duas crianças é mais difícil. Tem que ter muita paciência [...] não é fácil, tem que ficar o tempo inteiro alerta com ele, mas tem dia que ele vai quase o dia bonzinho, tem dia que ele fica insuportável. (E6)

É importante ressaltar que se torna imprescindível voltar a atenção também aos cuidadores de idosos com DA, sendo que esses desgastes a que estão expostos, tanto físico, emocional e até mesmo financeiro, podem acarretar consequências para o cuidador, transformando-o em um doente em potencial. ${ }^{8}$

A literatura demonstra que cuidadores de portadores de DA, por causa do desgaste causado pela sobrecarga de trabalho, tendem a apresentar sinais e sintomas físicos e psíquicos, como estresse, insônia, depressão e aumento na taxa de automedicação. ${ }^{21}$ 


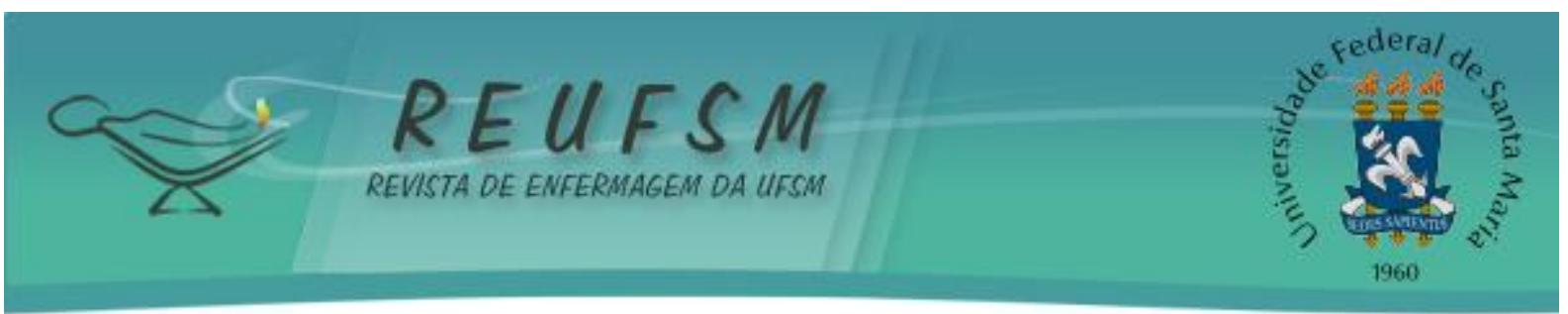

Diante disso, os cuidadores também mencionaram o sentimento de obrigação para com o cuidar do seu familiar doente.

[...] ainda mais que é minha mãe ainda, aí que você tem que ter mais paciência ainda. (E2)

\section{[...] é difícil, mas é minha mãe, eu cuido com todo prazer. (E4)}

[...] a gente cuida com muito amor, com muito carinho. Claro, a gente sente tristeza, mas eu cuido dela com prazer, graças a Deus. (E8)

Quando os cuidadores se referiam ao seu dever, gratidão ou responsabilidade de, como filhos, prestar apoio aos seus pais, estavam remetendo a uma obrigação moral e ética determinada pelo ato de cuidar. ${ }^{22}$

Esse compromisso de cuidar do idoso doente decorrente do cumprimento do papel social como filho pode ser um dos fatores estressantes que o cuidador vivencia no processo de cuidado. $^{23}$

Os filhos percebem que cuidar de seu familiar doente é sua obrigação, uma vez que em momentos anteriores da vida este estava na posição de cuidador. De tal modo, agora ocorre a inversão de papéis entre eles como uma forma de retribuir a dedicação de tempo e cuidado. ${ }^{23}$

Nota-se que o acúmulo de atividades, aliado à falta de colaboração de outros membros da família, gera para o cuidador um sentimento de impotência e significativo desgaste pessoal, evidenciando um despreparo no planejamento de cuidados dos doentes com DA, uma vez que poucas pessoas se dispõem a assumir essa tarefa. ${ }^{8}$

Sendo assim, a ajuda recebida de outros membros da família, de amigos e de profissionais da saúde torna-se um importante meio de fortalecer o sentimento de apoio e envolvimento desse cuidador e um consequente desempenho adequado desse papel. ${ }^{24}$

Podem-se citar a ajuda nas atividades diárias, o conforto, o carinho e a atenção que são prestados ao paciente, como sendo as melhores formas de bem-estar para ele, pois ainda não são conhecidos medicamentos capazes de evitar ou interromper a progressão da doença, visto que a ausência de um diagnóstico preciso e a inconsistência das causas da doença tornam o tratamento precário, tendo, assim, este o objetivo de retardar a evolução da DA, uma vez que ainda não se conhece a cura. ${ }^{4,7}$

\section{CONSIDERAÇÕES FINAIS}

A doença de Alzheimer configura-se como um problema que atinge não só a vida do doente, mas, de todos que estão à sua volta, principalmente a de seus cuidadores.

A partir dos dados obtidos, percebeu-se que o cuidador necessita de atenção e de que sejam articuladas estratégias de intervenções psicoeducativas para estes, para melhorar a sua qualidade de vida, uma vez que, ao assumir o papel de cuidador, passará a exercer funções muitas vezes cansativas, repetitivas e desgastantes.

É notório que o conhecimento dos cuidadores a respeito da doença de Alzheimer é limitado, o que acaba dificultando o planejamento dos cuidados ao portador. Assim, o cuidado prestado passa a ser baseado num conjunto de opiniões, impostos muitas vezes pela tradição familiar, advindos do senso comum e em grande parte adquiridos também por meio da mídia.

Cabe ao enfermeiro, como parte da equipe de saúde, orientar os cuidadores quanto à progressiva dependência do idoso consequente à doença de Alzheimer, assim como indicar estratégias para desempenhar as práticas de cuidados inerentes a evolução 


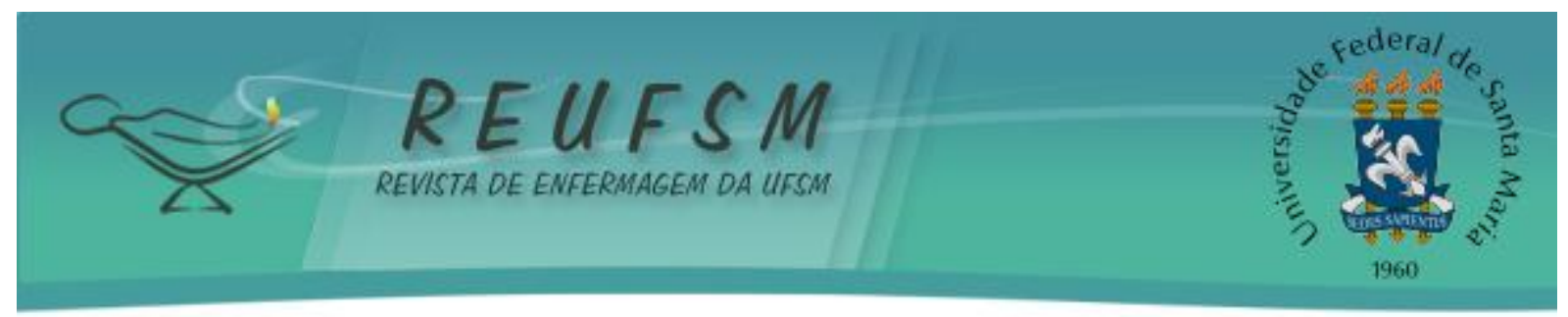

da doença de Alzheimer. No campo da prevenção de doenças e promoção da saúde, o enfermeiro deve, com um olhar amplo, identificar as manifestações da DA nos pacientes e alertar os envolvidos a buscarem orientações e cuidados necessários.

\section{REFERÊNCIAS}

1. Silva SPN, Aquino CAG, Barbosa TLA, Silva CSO, Gomes LMX. A perspectiva do cuidador frente ao idoso com a Doença de Alzheimer. Rev Pesqui Cuid Fundam [Internet]. 2013 jan/mar [acesso em 2013 abr 14];5(1):3333-42. Disponível em: http://www.seer.unirio.br/index.php/cuidadofundamental/article/view/1970/pdf_691.

2. Araújo CLO, Nicoli JS. Uma revisão bibliográfica das principais demências que acometem a população brasileira. Rev Kairós. 2010;13(1):231-44.

3. Domingues MARC, Santos CF, Quintans JR. Doença de Alzheimer: o perfil dos cuidadores que utilizam o serviço de apoio telefônico da ABRAz - Associação Brasileira de Alzheimer. Mundo Saúde. 2009;33(1):161-9.

4. Freitas ICC, Paula KCC, Soares JL, Parente ACM. Convivendo com o portador de Alzheimer: perspectivas do cuidador. Rev Bras Enferm [Internet]. 2008 jul-ago [acesso em 2013 mar 20];61(4):508-13. Disponível em http://www.scielo.br/pdf/reben/v61n4/18.pdf.

5. Itha S, Zamberlan C, Gehlen MH, Dias MV, Nicola GDO, Backes DS. Qualidade de vida do familiar cuidador de idosos com Alzheimer: contribuição de um projeto de extensão. Cogitare Enferm. 2012;17(2):270-6.

6. Seima MD. Relação/Participação no cuidado entre o cuidador familiar e o idoso com Alzheimer [dissertação]. Curitiba: Universidade Federal do Paraná; 2010. 157 f.

7. Arruda MC, Alvarez AM, Gonçalves LHT. O familiar cuidador de portador de Doença de Alzheimer participante de um grupo de ajuda mútua. Ciênc Cuid Saúde. 2008;7(3):339-45.

8. Lenardt MH, Silva SC, Willig MH, Seima MD. O idoso portador da Doença de Alzheimer: o cuidado e o conhecimento do cuidador familiar. REME Rev Min Enferm. 2010 jul/set;14(3): 301-7.

9. Silveira CL, Budó MLD, Silva FM, Durgante VL, Wunsch S, Simon BS, et al. Cuidadora de familiar com doença crônica incapacitante: percepções, motivações e repercussões. Rev Enferm UFSM [Internet]. 2012 [acesso 2013 mar 10];2(1):67-78. Disponível em: http://cascavel.ufsm.br/revistas/ojs-2.2.2/index.php/reufsm/article/view/3828/3128.

10. Minayo MCS. Pesquisa social: teoria, método e criatividade. 30a ed. Petrópolis: Vozes; 2011.

11. Fontanella BJB, Luchesi BM, Saldel MG, Ricas J, Turato ER, Melo DG. Amostragem em pesquisas qualitativas: proposta de procedimentos para constatar saturação teórica. Cad Saúde Pública. 2011;27(2):389-93.

12. Bardin L. Análise de conteúdo. São Paulo: Edições 70; 2011. 229 p.

13. Brasil. Ministério da Saúde. Conselho Nacional de Saúde. Resolução CNS no 196, de 10 de outubro de 1996. Aprova diretrizes e normas regulamentadoras de pesquisas envolvendo seres humanos. Brasília: Ministério da Saúde; 1996.

14. Paula JA, Roque FP, Araújo FS. Qualidade de vida em cuidadores de idosos portadores de demência de Alzheimer. J Bras Psiquiatr [Internet]. 2008 [acesso em 2013 mar 


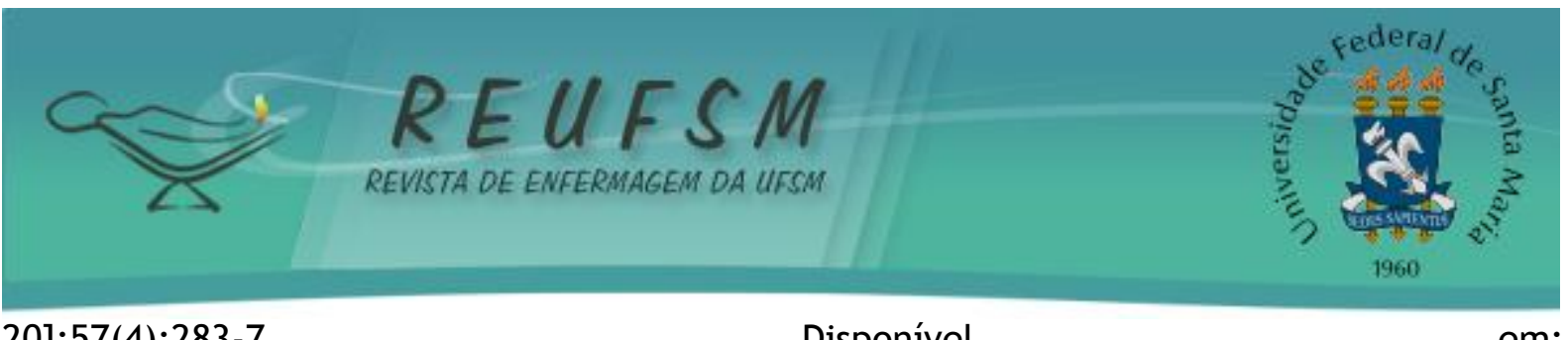

20];57(4):283-7.

Disponível

em:

http: / / www.scielo.br/scielo.php?script=sci_arttext\&pid=S004720852008000400011.

15. Cruz MN, Hamdan AC. O impacto da Doença de Alzheimer no cuidador. Psicol Estud [Internet]. 2008 [acesso em 2013 mar 20];13(2):223-9. Disponível em: http: / / www.scielo.br/scielo.php?script=sci_arttext\&pid=S141373722008000200004.

16. Santana RF, Almeida KS, Savoldi NAM. Indicativos de aplicabilidade das orientações de enfermagem no cotidiano de cuidadores de portadores de Alzheimer. Rev Esc Enferm USP [Internet]. 2009 jun [acesso em 2012 nov 12];43(2):459-64. Disponível em: http://www.scielo.br/pdf/reeusp/v43n2/a28v43n2.pdf.

17. Garces SBB, Krug MR, Hansen D, Brunelli AV, Costa FTL, Rosa CB, et al. Avaliação da resiliência do cuidador de idosos com Alzheimer. Rev Bras Geriatr Gerontol. 2012;15(2):335-52.

18. Sales ACS, Reginato BC, Pessalacia JDR, Kuznier TP. Conhecimento da equipe de enfermagem quanto aos cuidados com idoso portador da Doença de Alzheimer. Rev Enferm Cent O Min [Internet]. 2011 out/dez; [acesso em 2012 nov 12];1(4):492-502. Disponível em: http://www.seer.ufsj.edu.br/index.php/recom/article/view/141/239.

19. Resende MC, Turra DD, Alves F, Pereira FB, Santos SAP, Trevisan VC. Cuidar de idosos com Alzheimer: influências sociais, físicas e psicológicas envolvidas nesta tarefa. Rev Bras Ciênc Envelhec Human. 2008 jan/jun;5(1):19-31.

20. Nunes WA, Mendes AG, Fleiter M. A percepção do enfermeiro frente as dificuldades do portador de Alzheimer [Internet]. In: Anais do III Conclave dos Acadêmicos de Enfermagem da Universidade Positivo - CONAENF. Curitiba; 2011. p. 51-4. Disponível em: http://enfermagem.up.com.br/cmspositivo/uploads/imagens/files/Anais_Conaenf_2011\%5 B1\%5D.pdf.

21. Dornelles ARA. Uma intervenção psicoeducativa com cuidadores de idosos com demência [dissertação]. São Carlos (SP): Universidade Federal de São Carlos, Departamento de Psicologia; 2010. 145 p.

22. Falcão DVS, Bucher-Maluschke JSNF. Filhas que cuidam de pais/mães com provável/possível Doença de Alzheimer. Rev Estud Psicol. 2008;13(3):245-56.

23. Oliveira APP, Caldana RHL. As repercussões do cuidado na vida do cuidador familiar do idoso com demência de Alzheimer. Saúde Soc [Internet]. 2012 [acesso em 2013 abr 14];21(3):675-85. Disponível

em:

http: / / www.scielo.br/scielo.php?pid=S010412902012000300013\&script=sci_arttext.

24. Gaioli CCLO, Furegato ARF, Santos JLF. Perfil de cuidadores de idosos com doença de Alzheimer associado à resiliência. Texto \& Contexto Enferm. 2012 jan-mar;21(1):150-7.

Data de recebimento: $31 / 07 / 2013$

Data de aceite: 20/01/2014

Contato com autor responsável: Lídia Gonçalves Rabelo de Souza Almeida

Endereço postal: Rua Padre Guilherme Nunes, 325 - Bairro: Adelino Mano - Carmo do

Cajuru/MG - CEP: 35510-000

E-mail: lidiagrsalmeida@hotmail.com 